Supporting Information For:

\title{
Has Monopotassium Phthalocyanine, KPc, Been Synthesized?
}

Julie A. Cissell and Thomas P. Vaid 

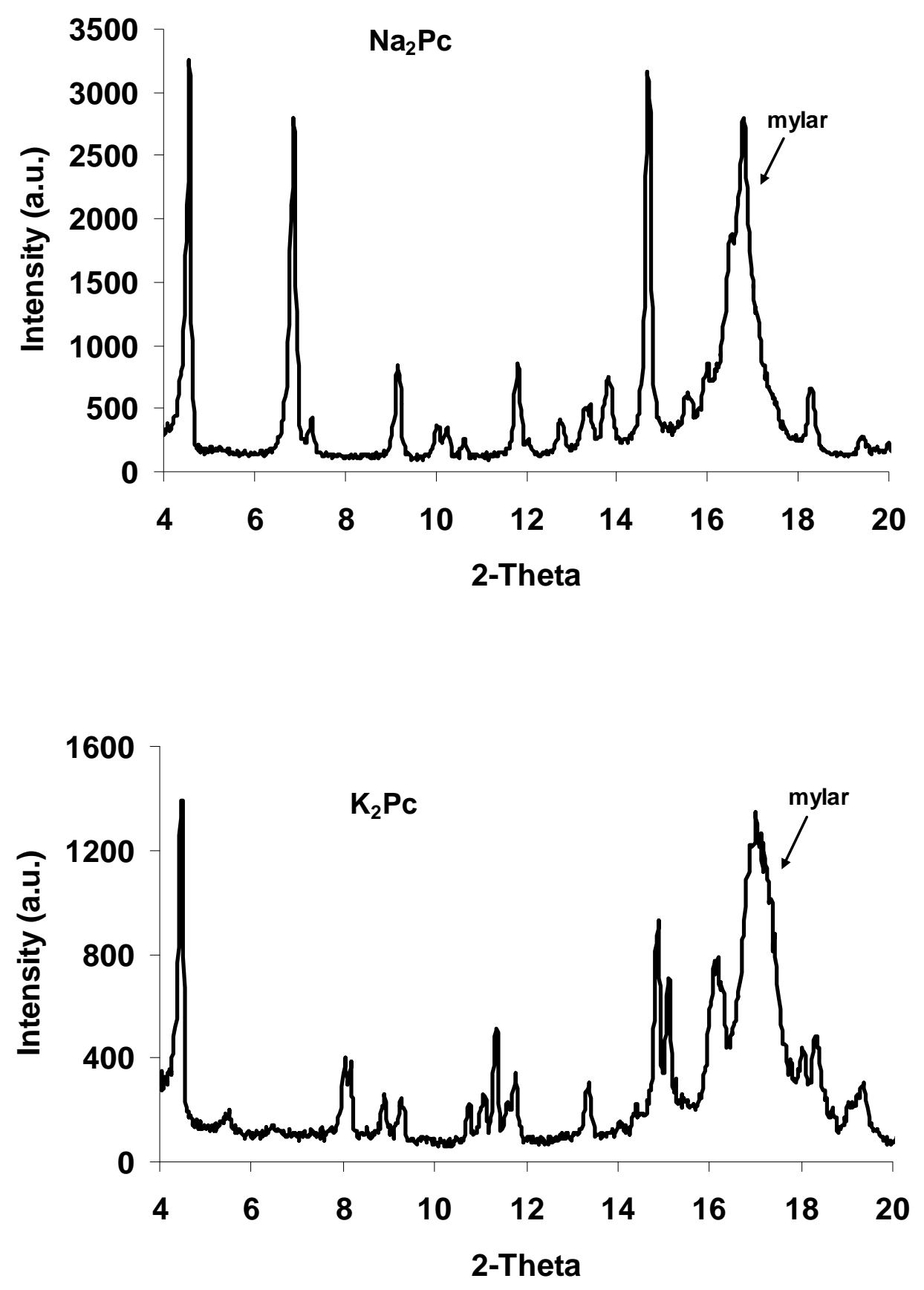

Figure S1. Powder X-ray diffraction patterns of $\mathrm{Na}_{2} \mathrm{Pc}$ (top) and $\mathrm{K}_{2} \mathrm{Pc}$ (bottom) prepared by the Linstead method. Both patterns are adjusted to correspond to an X-ray wavelength of $1.0008 \AA$. 